http://jmscr.igmpublication.org/home/

ISSN (e)-2347-176x ISSN (p) 2455-0450

crossref DOI: https://dx.doi.org/10.18535/jmscr/v7i7.77

Journal Of Medical Science And Clinical Research

IGM Publication

An official Publication of IGM Publication

\title{
Assessment of Excessive Vaginal Discharge among Rural Women: A Hospital Based Study
}

\author{
Authors \\ Sawai Khatri ${ }^{1}$, Kheta Ram Soni ${ }^{1 *}$
}

${ }^{1}$ Senior Resident, Department of Obstetrics \& Gynaecology, Government Medical College, Barmer, Rajasthan, India

*Corresponding Author

Dr Kheta Ram Soni

Senior Resident, Department of Obstetrics \& Gynaecology, Government Medical College, Barmer,

Rajasthan, India

\begin{abstract}
Background: Being a healthy woman is important to have good reproductive health and to have a healthy baby. Symptomatic vaginal discharge in the women of reproductive age group is responsible for 5-10 million OPD visits per year throughout the world. Hence; we planned the present study to assess vaginal discharge among rural women.

Materials \& Methods: A total of 100 subjects were enrolled in the present study. Detail demographic data of all the subjects was obtained. A self-framed questionnaire was prepared are complete history of present illness and past medical history of all the subjects was obtained. All the results were recorded in Microsoft excel sheet and were analyzed SPSS software. Chi-square test was used for evaluation of significance.

Results: Non-significant results were obtained while assessing the age-wise distribution of subjects. Among the 100 subjects, 80 subjects were married while 8 subjects were widow and 12 subjects were divorced. 80 subjects were unemployed and 20 subjects were employed. Anxiety was present as a risk factor in 69 subjects with vaginal discharge. Significant results were obtained while assessing the marital status and presence of anxiety as a risk factor for vaginal discharge.

Conclusion: Knowledge of risk factors of vaginal discharge could help in reducing its incidence.

Keywords: Discharge, Vaginal, Women.
\end{abstract}

\section{Introduction}

Being a healthy woman is important to have good reproductive health and to have a healthy baby. Reproductive health problems constitute the leading cause of ill health in women of reproductive age group worldwide especially in developing countries. Ignoring these preventable and treatable conditions can lead to distressful situations among many women. ${ }^{1-3}$

Symptomatic vaginal discharge in the women of reproductive age group is responsible for 5-10 million OPD visits per year throughout the world. Abnormal vaginal discharge also predisposes to significant morbidity in the form of pelvic inflammatory diseases, infertility, endometriosis, cuff cellulitis, urethral syndrome, pregnancy loss, preterm labour, increase susceptibility to sexually transmitted infections (STI), including HIV and to be associated with low birth weight and preterm birth. $^{4-6}$

Hence; we planned the present study to assess vaginal discharge among rural women. 


\section{Materials \& Methods}

The present study was conducted in the department of Obstetrics \&Gynaecology of Government Medical College, Barmer, Rajasthan, India. It included assessment of vaginal discharge among rural women. Ethical approval was obtained from institutional ethical committee and written consent was obtained after explaining in detail the entire research protocol. A total of 100 subjects were enrolled in the present study. Inclusion criteria for the present study included:

- Subjects with history of vaginal discharge,

- Subjects more than 20 years and less than 45 years of age

- Subjects with negative history of pregnancy

After meeting the inclusion criteria, detail demographic data of all the subjects was obtained. Unmarried subjects were excluded. A self-framed questionnaire was prepared are complete history of present illness and past medical history of all the subjects was obtained. All the results were recorded in Microsoft excel sheet and were analyzed SPSS software. Chi- square test was used for evaluation of significance.

\section{Results}

In the present study, a total of 100 subjects were analyzed. Mean age of the subjects of the present study was 38.2 years. Majority of the subjects (40 percent) belonged to the age group of more than 35 years. Non-significant results were obtained while assessing the age-wise distribution of subjects. Among the 100 subjects, 80 subjects were married while 8 subjects were widow and 12 subjects were divorced. 80 subjects were unemployed and 20 subjects were employed. Anxiety was present as a risk factor in 69 subjects with vaginal discharge. Significant results were obtained while assessing the marital status and presence of anxiety as a risk factor for vaginal discharge.

Table 1: Age-wise distribution of women with vaginal discharge

\begin{tabular}{|l|c|c|c|}
\hline \multicolumn{2}{|l|}{ Parameter } & $\begin{array}{c}\text { Number of } \\
\text { patients }\end{array}$ & \\
\hline \multirow{2}{*}{$\begin{array}{l}\text { Age group } \\
\text { (years) }\end{array}$} & Less than 25 & $\mathbf{2 5}$ & \multirow{2}{*}{0.48} \\
\cline { 2 - 3 } & $\mathbf{2 5}$ to 35 & $\mathbf{3 5}$ & \\
\cline { 2 - 3 } & More than 35 & $\mathbf{4 0}$ & \\
\hline
\end{tabular}

Table 2: Clinical data of women with vaginal discharge

\begin{tabular}{|l|c|c|c|}
\hline \multicolumn{2}{|l|}{ Parameter } & $\begin{array}{c}\text { Number of } \\
\text { patients }\end{array}$ & \multirow{2}{*}{ p- value } \\
\hline \multirow{3}{*}{ Marital status } & Married & $\mathbf{8 0}$ & \multirow{2}{*}{$\begin{array}{c}0.00 \\
\text { (Significant) }\end{array}$} \\
\cline { 2 - 3 } & Widow & $\mathbf{8}$ & \\
\cline { 2 - 3 } & Divorced & $\mathbf{1 2}$ & \\
\hline \multirow{2}{*}{$\begin{array}{c}\text { Employment } \\
\text { status }\end{array}$} & Unemployed & $\mathbf{8 0}$ & 0.00 \\
\cline { 2 - 3 } Anxiety & Employed & $\mathbf{2 0}$ & (Significant) \\
\cline { 2 - 3 } & Yes & $\mathbf{6 9}$ & 0.00 \\
& No & $\mathbf{3 1}$ & (Significant) \\
\hline
\end{tabular}

Table 2: Clinical data of women with vaginal discharge

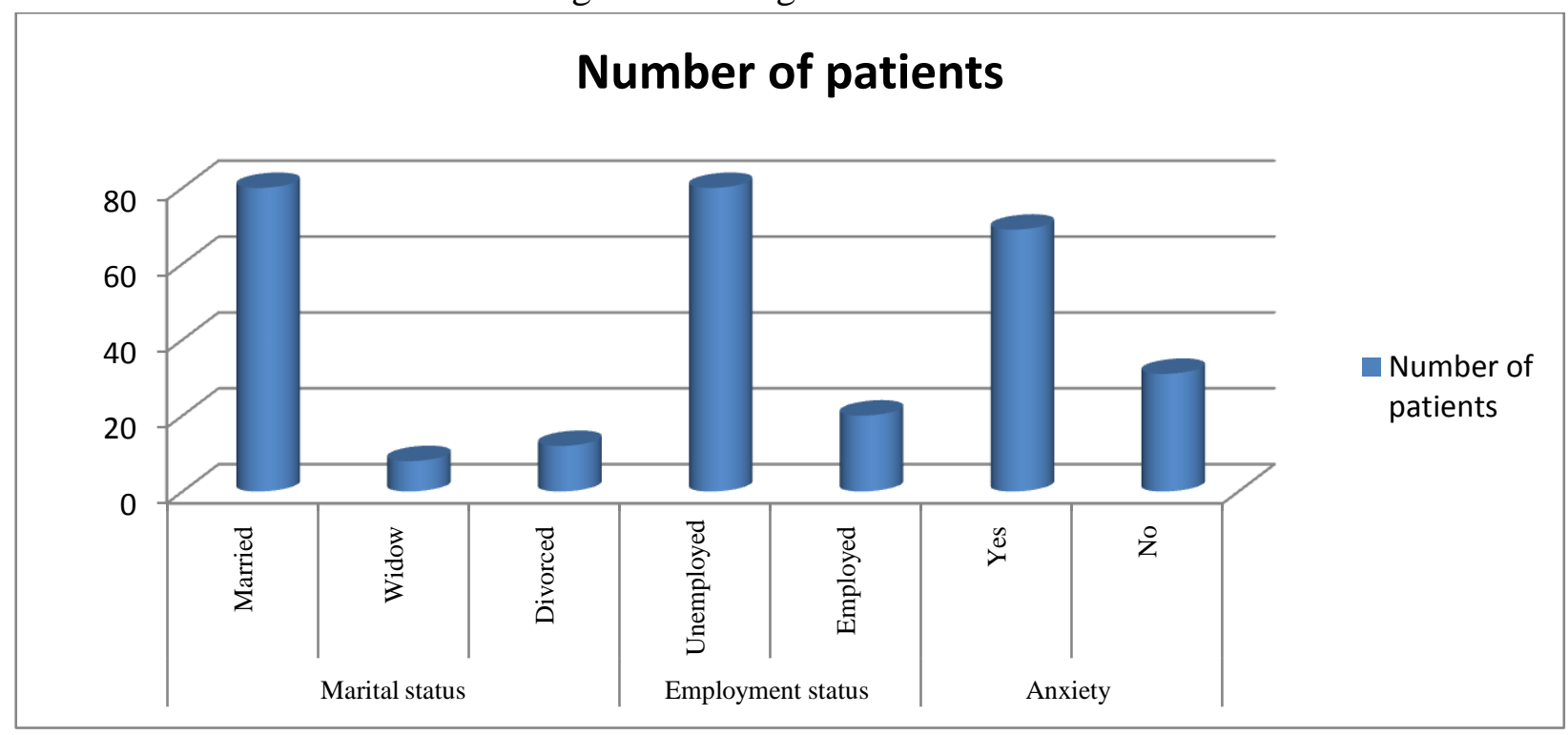




\section{Discussion}

Reproductive tract infections (RTIs) impose heavy burden of pathologies and adversely affect reproductive health. Across the world, they result in greater illness among both males and females. However; their effect of more sever and widespread among females. These spectrums of pathologies frequently go neglected and undiagnosed, which further results in greater complications events including infertility, ectopic pregnancy and cervical cancer. 7,8

In the present study, a total of 100 subjects were analyzed. Mean age of the subjects of the present study was 38.2 years. Majority of the subjects (40 percent) belonged to the age group of more than 35 years. Non-significant results were obtained while assessing the age-wise distribution of subjects.In one of the past studies, microbial profile of the symptomatic vaginal discharge was assessed by Masand DL et al. They also explored its utility in the management of genital tract infection. Their study group included sexually active females among the age group of eighteen years to forty five years who attended the OPD of department of gynecology. Total sample size of their study was 100 females. They conducted the thorough clinical and pelvic examination of all the females after taking the informed written consent. Collection of 2 vaginal swabs and blood samples was done for examination. This was followed by staining and culture examination. They employed the ELISA technique for detecting Chlamydia trachomatis IgM antibodies. In eighty nine percent of the cases, specific diagnosis was obtained, while in the remaining 11 percent of the cases, no specific etiology was observed. From the results, they concluded that in subjects with symptomatic vaginal discharge, there is urgent need of active management using specific antimicrobial drugs. ${ }^{9}$ Among the 100 subjects, 80 subjects were married while 8 subjects were widow and 12 subjects were divorced. 80 subjects were unemployed and 20 subjects were employed. Anxiety was present as a risk factor in 69 subjects with vaginal discharge. Significant results were obtained while assessing the marital status and presence of anxiety as a risk factor for vaginal discharge.Evaluation of female's awareness in relation to vaginal discharge was done by Zaher EH et al. They made a questionnaire and gave it to all the participants. The questionnaire was made with the aim of collecting detailed information regarding the personal history, family history and past medical history of all the subjects. The questionnaire also consisted of few components for assessing the knowledge of the subject in relation to vaginal discharge. They also intended to obtain the true incidence of abnormal vaginal discharge among females included in their study. The results of their study showed that abnormal vaginal discharge was present among less than one fourth of the subjects. From the results, they concluded that extremely poor awareness is present among females in relation to vaginal discharge. ${ }^{10}$ Sivaranjini Ret al assessed the etiologic spectrum of vaginal discharge in Indian population. They analyzed a total of 400 females who presented with vaginal discharge. They observed that diagnosis was accurately established in 303 subjects. From the results, they concluded that the pattern of infectious etiologic factor of vaginal discharge present in their study was comparable with the other studies in India. ${ }^{11}$

\section{Conclusion}

Under the light of above obtained data, the authors conclude that knowledge of risk factors of vaginal discharge could help in reducing its incidence.

\section{References}

1. MM Singh, R Devi, S Garg, M Mehra. Effectiveness of syndromic approach in management of reproductive tract infections in women. Indian $\mathbf{J}$ Med Sci. 2001;55:209-14.

2. $\mathrm{P}$ Madhivanan, $\mathrm{K}$ Krupp, V Chandrasekaran, C Karat, AArun, CR Cohen. Prevalence and correlates of Bacterial vaginosis among young women of reproductive age in Mysore, India. 
Indian J Med Microbiol. 2008;26(2):13237.

3. Gulati SC, Chaurasia AR, Singh RM. Women'S reproductive morbidity and treatment-seeking behaviour in India. Asian Popul Stud. 2009;5(1):61-84.

4. Adıbelli D, Kılınç NO, Akpak YK, Kılıç D. Genital hygiene behaviors and associated factors in women living in rural areas of Turkey. Elect Med J. 2014;2(3): 210-214.

5. JE Tolosa, S Chaithongwongwatthana, S Daly, WW Maw, H Gaitan, P Lumbiganon, et al. The international infection in pregnancy (IIP) study: variations in the prevalence of Bacterial vaginosis and distribution of morphotypes in vaginal smears among pregnant women. Am J Obstet Gynecol. 2006;195(5):11981204.

6. H Moi. Prevalence of Bacterial vaginosis and its association with genital infections, inflammation and contraceptive methods in women attending sexually transmitted disease and primary health clinics. Int $\mathbf{J}$ STD AIDS. 1990;1(1):86-94.

7. Karou SD, Djigma F, Sagna T, Nadembega C, Zeba M, Kabre A, et al. Antimicrobial resistance of abnormal vaginal discharges microorganisms in Ouagadougou, Burkina Faso. Asian Pac J Trop Biomed. 2012;2(4):294-297.

8. World Health Organization. Sexually Transmitted and Other Reproductive Tract Infections Integrating STI/ RTI Care for Reproductive Health: A Guide to Essential Practice. Geneva: WHO; 2005

9. Masand DL, Patel J, Gupta S. Utility of microbiological profile of symptomatic vaginal discharge in rural women of reproductive age group. J ClinDiagn Res. 2015;9(3):QC04-QC7. doi:10.7860/JCDR/2015/12161.5623
10. Zaher EH. Awareness of Women Regarding Vaginal Discharge. IOSR Journal of Nursing and Health Science (IOSR-JNHS2017; 6 (1): 1-12.

11. Sivaranjini R, Jaisankar T, Thappa DM, et al. Spectrum of vaginal discharge in a tertiary care setting. Trop Parasitol. 2013;3(2):135-139. 